\title{
Punica granatum leave extract as green corrosion inhibitor for mild steel in Hydrochloric acid
}

\author{
Y. Abboud ${ }^{1,2, a}$, A. Chagraoui ${ }^{1}$, O. Tanane ${ }^{1}$, A. El Bouari ${ }^{1}$ and H. Hannache ${ }^{2}$ \\ ${ }^{1}$ Laboratoire de Physico-Chimie des Matériaux Appliqués, Faculté des Sciences Ben M'sik, Casablanca \\ ${ }^{2}$ Centre d'Analyse et de Recherche, Faculté des Sciences Ben M'sik, Casablanca, Morocco
}

\begin{abstract}
Leave of Punica granatum extract (LPGE) as green inhibitor for the corrosion of mild steel in $1 \mathrm{M} \mathrm{HCl}$ solution was studied using weight-loss and potentiodynamic polarization measurements. The results obtained revealed that LPGE has fairly good inhibiting properties for mild steel corrosion in $1 \mathrm{M} \mathrm{HCl}$ solution, with efficiency of around $94 \%$ at a concentration of $1 \mathrm{~g} / \mathrm{l}$. The inhibition was of a mixed anodic-cathodic nature. The film which is formed over the metal surface was analysed by FT-IR spectroscopy. Further examination using X-ray diffraction confirms the role of LPGE as an effective corrosion inhibitor for mild steel in acid media.
\end{abstract}

\section{INTRODUCTION}

The toxic nature and high cost of organic acid inhibitors have necessitated research activity in recent time toward finding alternative acid corrosion inhibitors. Various parts of plants - seeds, fruit, and leaves, were extracted and used as corrosion inhibitors [1-7]. Punica granatum, commonly known as pomegranate is reported to be a rich source of anthocyanins (delphinidin, cyaniding, and pelargonidin), phenolic compounds (including hydrolysable tannins such as punicalin, pedunculagin, punicalagin, gallagic, and ellagic acid), and organic acids alleged to be responsible for its medicinal properties [8,9]. A survey of literature revealed that there are few reports on the corrosion behaviour of mild steel in the presence of pomegranate extracts. Earlier, Saleh et al $[10,11]$ studied the effect of various naturally occurring substance, among them pomegranate juice and peel extract on the dissolution of steel in $\mathrm{HCl}$ solutions using weight loss and thermometric techniques. Quraishi et al [12] investigated several plant products as corrosion inhibitors, and found that that pomegranate shell gave adequate protection for mild steel in $3 \% \mathrm{NaCl}$. Recently, work has been emphasized on the use of Punica granatum peel as corrosion inhibitor for mild steel and Brass in acidic solutions $[13,14]$.

The satisfactory result obtained by peel and juice of pomegranate as corrosion inhibitors for mild steel in acidic media have prompted us to test other parts of the plant which has not yet been studied. Therefore, this investigation deals with the performance of leaves extract of pomegranate on mild steel corrosion in $\mathrm{HCl} 1 \mathrm{M}$ using chemical and electrochemical techniques. Inhibited metallic surface was also examined by FT-IR and DRX to establish the corrosion inhibitive property of this part of pomegranate extract in $\mathrm{HCl}$ solution.

\section{EXPERIMENTAL}

\subsection{Materials preparation}

Tests were performed on carbon steel specimens with weight percentage composition as follows: C, 0.05; Mn, 0.6; P, 0.36; $\mathrm{Si}, 0.3$; and the balance Fe. The blank corrodent was $1.0 \mathrm{M} \mathrm{HCl}$ solution. Stock solutions of the plant extract were prepared by boiling weighed amounts of the dried and ground leaves of Punica granatum under reflux for $3 \mathrm{~h}$ in $1.0 \mathrm{M} \mathrm{HCl}$ solution. From the stock solution, inhibitor test solutions were prepared in the concentration range $0.2-1 \mathrm{~g} / \mathrm{L}$.

\subsection{Weight loss measurements}

Gravimetric measurements were carried out at $298^{\circ} \mathrm{K}$ temperature for $6 \mathrm{~h}$ time duration. The inhibition efficiency (\%) was determined by following equation:

$$
\mathrm{E}(\%)=\frac{\mathrm{W}_{0}-\mathrm{W}}{\mathrm{W}_{0}} \times 100 .
$$

Where $\mathrm{W}$ and $\mathrm{W}_{0}$ are the values of the average weight loss without and with addition of inhibitor.

\subsection{Potentiodynamic polarisation measurements}

Polarisation experiments were carried out in a conventional three-electrode cell. All polarisation curves were recorded with Amel potentiostat (model 2053) from cathodic potential of $-0.250 \mathrm{~V}$ vs. SCE to an anodic potential of $+0.250 \mathrm{~V}$ vs. SCE with respect to the open circuit potential at a sweep rate $20 \mathrm{mVmn}^{-1}$ in aerated condition to make the conditions identical to weight loss measurements. The corrosion inhibition efficiency E (\%) was defined as:

$$
\mathrm{E}(\%)=\frac{\mathrm{I}_{\text {corr }}-\mathrm{I}_{\text {corr }}^{\mathrm{inh}}}{\mathrm{I}_{\text {corr }}} \times 100 .
$$

a e-mail: Youabboud@yahoo.fr 
Table 1. Corrosion parameters for mild steel in $1 \mathrm{M} \mathrm{HCl}$ obtained from Weight loss measurement.

\begin{tabular}{lccc}
\hline LPGE $(\mathrm{g} / \mathrm{l})$ & $\Delta \mathrm{m}(\mathrm{mg})$ & $\mathrm{W}(\mathrm{mg} / \mathrm{cm} 2)$ & $\mathrm{E}(\%)$ \\
\hline $\mathrm{HCl} 1 \mathrm{M}$ & 7.75 & 1.938 & \\
0.2 & 2.86 & 0.71 & 63.36 \\
0.4 & 2.22 & 0.55 & 71.62 \\
0.6 & 1.61 & 0.40 & 79.36 \\
0.8 & 1.16 & 0.29 & 85.03 \\
1 & 0.46 & 0.12 & 93.80 \\
\hline
\end{tabular}

Where $I_{\text {corr }}$ and $I_{\text {corr }}^{\text {inh }}$ are the corrosion current densities without and with the addition of various concentration of the inhibitor.

\subsection{Surface examinations}

The nature of the film formed on the surface on the metal specimens was analysed by FT-IR and XRD. The infrared spectrum was obtained as $\mathrm{KBr}$ pellets on a Bruker Tensor27 spectrophotometer while the corrosion products were identified by X-Ray diffraction (model: XRD-Bruker D8 Advance).

\section{RESULTS AND DISCUSSION}

\subsection{Weight loss measurements}

The results obtained from weight loss measurement (Table 1) indicates that the mild steel corrosion is reduced by the presence of LPGE in $1 \mathrm{M} \mathrm{HCl}$ at all concentrations used in this study, since there is a general decrease in the original weight of mild steel at the end of the corrosion monitoring process. This may be ascribed to the adsorption of inhibitor on the mild steel surface, producing a barrier, which isolates the surface from the corrosion environment. It has also been observed that the corrosion rate decrease gradually with increasing inhibitor concentration and the degree of inhibition depends on the concentration of LPGE. The inhibition efficiency was estimated to be $63 \%$ even at low concentration $(0.2 \mathrm{~g} / \mathrm{l})$ and reaches $94 \%$ at a concentration of $(1 \mathrm{~g} / \mathrm{l})$. This behaviour is due to the fact that the adsorption coverage of inhibitor on metal surface increases with the inhibitor concentration. Such remarkable performances may be due to, the high molecular weight, the presence of electron donation groups $(\mathrm{C}=\mathrm{O}, \mathrm{O}-\mathrm{H})$ and the presence of aryl groups of tannins (punicalin and punicafolin); and flavone glycosides (luteolin and apigenin) which are the main constituents of punica granatum leaves [15].

\subsection{Electrochemical measurements}

Figure 1 shows the cathodic and anodic polarization curves of mild steel in $1 \mathrm{M} \mathrm{HCl}$ solution without and with different concentrations of LPGE at $298^{\circ} \mathrm{K}$. Values of all electrochemical parameters such as corrosion potential (Ecorr), cathodic and anodic Tafel slopes (bc, ba) and

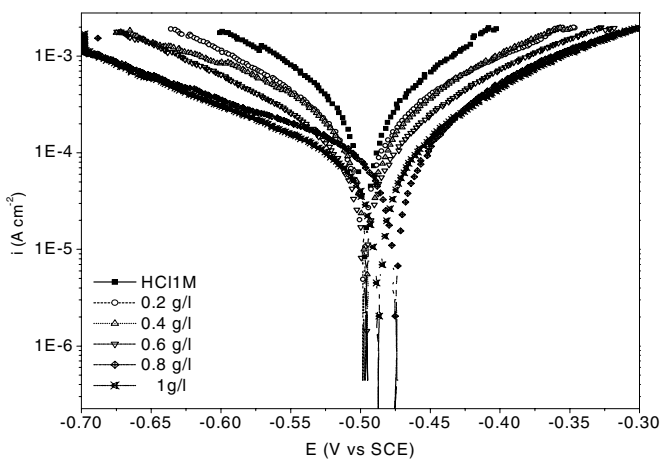

Figure 1. Tafel polarisation curves of LPGE in $1 \mathrm{M} \mathrm{HCl}$ on mild steel at $298^{\circ} \mathrm{K}$.

Table 2. Electrochemical parameters for mild steel obtained from Tafel polarization curves.

\begin{tabular}{lccccc}
\hline $\begin{array}{l}\text { LPGE } \\
(\mathrm{g} / \mathrm{l})\end{array}$ & $\begin{array}{c}\mathrm{E}_{\text {corr }} \\
(\mathrm{mV})\end{array}$ & $\begin{array}{c}-\mathrm{b}_{\mathrm{c}} \\
(\mathrm{mVdec})\end{array}$ & $\begin{array}{c}\mathrm{b}_{\mathrm{a}} \\
(\mathrm{mVdec})\end{array}$ & $\begin{array}{c}\mathrm{i}_{\text {corr }} \\
\left(\mu \mathrm{Acm}^{-2}\right)\end{array}$ & $\begin{array}{c}\mathrm{E} \\
(\%)\end{array}$ \\
\hline HCl 1M & -496 & 134.38 & 82.83 & 356.46 & \\
0.2 & -498 & 131.41 & 108.01 & 138.68 & 61.09 \\
0.4 & -494 & 135.72 & 93.99 & 111.52 & 68.71 \\
0.6 & -496 & 138.64 & 104.25 & 85.91 & 75.89 \\
0.8 & -475 & 191.13 & 105.27 & 65.05 & 81.75 \\
1 & -487 & 160.95 & 103.81 & 24.41 & 93.15 \\
\hline
\end{tabular}

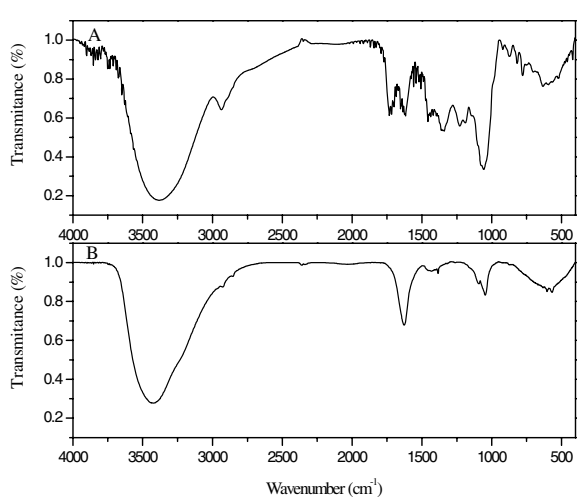

Figure 2. IR absorption spectra of LPGE and the film formed over i mild steel.

corrosion current density (Icorr) attained by extrapolation of Tafel lines, as well as inhibitor efficiency are listed in Table 2.

From Fig. 1, it is clear that the values of $\left(\mathrm{I}_{\text {corr }}\right)$ of mild steel in the inhibited solution were smaller than those for the inhibitor-free solution. This result shows that the addition of LPGE hindered the acid attack on the steel electrode. The polarization curves show that this inhibitor has an effect on both, the cathodic and anodic slopes (bc and ba) and suppressed both cathodic and anodic processes. This indicates a modification of the mechanism of cathodic hydrogen evolution as well as anodic dissolution of iron, which suggest that inhibitor powerfully inhibits the corrosion process of mild steel, and its ability as corrosion inhibitor is enhanced as its concentration is increased. The suppression of cathodic process can be due to the covering of the surface with monolayer due to the adsorbed inhibitor molecules. It can 


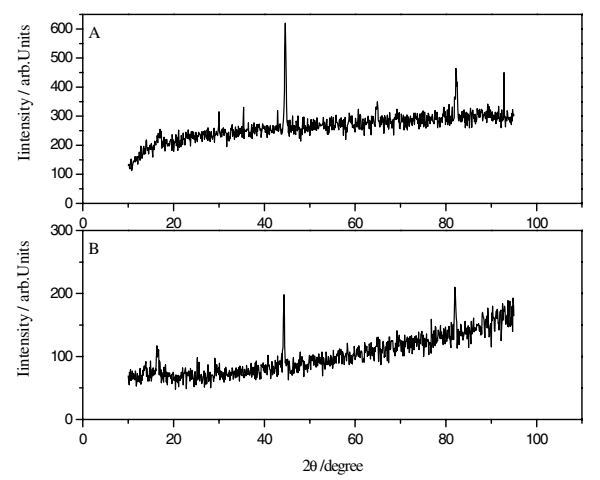

Figure 3. XDR pattern of the surface of mild steel after immerssion in $1 \mathrm{M} \mathrm{HCl}$ without and with LGPE.

also be seen from Table 2 that anodic Tafel slope (ba) increases in the presence of inhibitor. This observation may be ascribed to changes in the charge transfer coefficient for the anodic dissolution of iron by virtue of the presence of an additional energy barrier due to the presence of adsorbed inhibitor. Further inspection of Table 2 also reveals that Ecorr values do not show any significant change in the presence of various concentrations of the inhibitor suggesting that inhibitor is a mixed type in $1.0 \mathrm{M}$ $\mathrm{HCl}$, which influence both metal dissolution and hydrogen evolution $[16,17]$.

\subsection{Surface examination}

The infrared spectrum LPGE indicates the presence of Hydroxyl group (3500-3250 $\left.\mathrm{cm}^{-1}\right)$, ester group $\left(1700-1750 \mathrm{~cm}^{-1}\right)$, chromone carbonyl group (1630$1610 \mathrm{~cm}^{-1}$ ), aromatic Hydrogen group (3000-2920 $\mathrm{cm}^{-1}$ ) and aromatic ring $\left(1550,1094 \mathrm{~cm}^{-1}\right)$. By comparing the spectrum of adsorbed film with that of LPGE, we can conclude that certain peaks have been disappeared completely and some have shifted to higher frequency region. The presence of bands around 3425, 2920, 1620 and $1019 \mathrm{~cm}^{-1}$ characteristics to $\mathrm{OH}, \mathrm{CH}, \mathrm{C}=\mathrm{O}$ and $\mathrm{C}-\mathrm{O}$ stretching vibration frequencies confirm the presence of LPGE or at least, its complex with iron in the formed film. The disappearance and the shift of certain peaks to higher wavenumbers clearly proved that some interaction have been taking place over the metal surface.

The X-ray diffraction patterns of the surface of the mild steel specimens immersed in various test solutions are given in Fig. 3. Peaks at $2 \theta=30^{\circ}, 35.4^{\circ}, 42.9^{\circ}$ and $64.9^{\circ}$ can be assigned to oxides of iron. The peaks due to iron appear at $2 \theta=44.6^{\circ}, 82.3^{\circ}$ and $92.8^{\circ}$. Thus, it is observed that in absence of inhibitor (A), the surface of the metal contains iron oxides of $\mathrm{Fe}_{3} \mathrm{O}_{4}$ and $\mathrm{FeOOH}$.
The XDR patterns of inhibited surface (B) show the presence of iron peaks only, the peaks due to oxides of iron are found to be absent. The formation of adsorbed protective film on the surface of metal in the presence of LPGE is clearly reflected from these observations.

\section{CONCLUSION}

From the results it is evident that LPGE shows excellent inhibition properties for the corrosion of mild steel in $1 \mathrm{M} \mathrm{HCl}$ at $298^{\circ} \mathrm{K}$, and the inhibition efficiency increases with increase in the inhibitor concentration. The inhibitor efficiencies determined by weight loss and Tafel polarization methods are in reasonable agreement. Based on the Tafel polarization results, LPGE can be classified as mixed inhibitor. Surface analysis reveals formation of adsorbed protective film on the surface of metal.

\section{References}

[1] M. Lebrini, F. Robert, A. Lecante, C. Roos, Corros. Sci. 53 (2011) 687-695.

[2] K.P.V. Kumar, M.S.N. Pillai, G.R. Thusnavis, J. Mater. Sci. Technol. 27 (2011) 1143-1149.

[3] S. Deng, X. Li, Corros. Sci. 55 (2012) 407-415.

[4] K.L. Prabha, S. Rajam, A. Subramania, J. Chem. Pharm. Res. 4 (2012) 337-347.

[5] N. Gunavathy, S.C. Murugavel, E-J. Chem. 9 (2012) 487-495.

[6] L. Afia, R. Salghi, L. Bammou, Lh. Bazzi, B. Hammouti, L. Bazzi, Acta Metall. Sin. (Engl. Lett.) 25 (2012) 1-9.

[7] C. Selles, O. Benali, B. Tabti, L. Larabi, Y. Harek, J. Mater. Environ. Sci. 3 (2012) 206-219.

[8] M.G. Miguel, M.A. Neves, M.D. Antunes, J. Med. Plants. Res. 4 (2010) 2836-2847.

[9] J. Jurenka, Altern- Med- Rev. 13 (2008) 128-144.

[10] R.M. Saleh, A.A. El-Hosary, Proc. 13 th seminar on electrochemistry, CECRI, Karaikudi, India (1972).

[11] R.M. Saleh, A.A. Ismail, A.A. El-Hosary, Brit. Corros. J. 17 (1982) 131-135.

[12] M.A. Quraishi, I.H. Farooqi, P.A. Saini, Corrosion 55 (1999) 493-497.

[13] M. Behpour, S.M. Ghoreishi, M. Khayatkashani, N. Soltani, Corros. Sci. 131 (2012) 621-633.

[14] P.D. Rani1, S. Selvaraj, J. Phytology 2 (2010) 58-64.

[15] M.A. Nawwar, S.A. Hussein, I. Merfort, Phytochemistry 1994; 36: 793-798.

[16] M.A. Quraishi, D. Jamal, Mater. Chem. Phys. 78 (2003) 608-613.

[17] M.A. Quraishi, H.K. Sharma, Chem. Phys. 78 (2002) $18-21$. 